\title{
PENINGKATAN PEMAHAMAN PERAWAT PELAKSANA DALAM PENERAPAN KESELAMATAN PASIEN MELALUI PELATIHAN KESELAMATAN PASIEN
}

\author{
Sri Yulia ${ }^{1,2 *}$, Achir Yani S. Hamid ${ }^{3}$, Mustikasari ${ }^{3}$ \\ 1. STIKES Muhammadiyah Palembang, Palembang 30262, Indonesia \\ 2. Program Studi Magister Fakultas Ilmu Keperawatan Universitas Indonesia, Depok 16424, Indonesia \\ 3. Fakultas Ilmu Keperawatan Universitas Indonesia, Depok 16424, Indonesia \\ *Email:mylia_sriplg@yahoo.com
}

\begin{abstract}
Abstrak
Upaya membangun budaya keselamatan pasien memerlukan komitmen yang dipengaruhi pengetahuan perawat. Tujuan penelitian quasi experiment ini adalah untuk mengetahui pengaruh pelatihan keselamatan pasien terhadap pemahaman perawat pelaksana mengenai penerapan keselamatan pasien. Hasil penelitian pada 83 perawat pelaksana di RS XX (kelompok eksperimen) dan 83 perawat pelaksana di RS XY (kelompok kontrol) menunjukkan ada perbedaan yang bermakna pemahaman perawat pelaksana sebelum dan setelah mendapatkan pelatihan pada kelompok eksperimen $(p=0,000 ; \alpha=0,05)$ dan tidak ada perbedaan pada pemahaman perawat pelaksana sebelum dan setelah pada kelompok kontrol $(\mathrm{p}=0,417 ; \alpha=0,05)$. Rumah sakit perlu melakukan program pelatihan keselamatan pasien secara berkelanjutan dan mengembangkan standar kinerja untuk memfasilitasi transfer pengetahuan perawat.
\end{abstract}

Kata Kunci: keselamatan pasien, pelatihan, pemahaman, perawat pelaksana

\section{Abstract}

Efforts to build a culture of patient safety required commitment is influenced by knowledge of nurses. This quasi-experimental study aimed to describe the influence of patient safety training for nursing staff's comprehension of the implementation of patient safety's procedure. Results for 83 nursing staffs XX Hospital (experimental group) and 83 nursing staffs XY Hospital (control group) showed no significant differences in understanding nursing staffs before and after receiving training in the experimental group $(p=0.000 ; \alpha=0.05)$ and no difference in understanding nursing staffs before and after in the control group $(p=0.417 ; \alpha=0.05)$. Hospitals need to make patient safety training program on an ongoing basis and develop performance standards as a facilitation of transferred of nursing staff's knowledge.

Keywords: comprehension, nursing staffs, patient safety, training

\section{Pendahuluan}

Industri rumah sakit termasuk dalam kategori High Reliability Organizations (HRO), memungkinkan menjalankan pelayanan sebaik mungkin, walaupun memiliki kompleksitas proses dalam organisasi (Cahyono, 2008; Takagi \& Nakanishi, 2007). Rumah sakit yang menyadari kedudukan sebagai HRO mengedepankan peningkatan mutu pelayanan melalui pengembangan program keselamatan dan lingkungan kerja untuk membangun budaya keselamatan di kalangan perawat (Hughes, 2008).

Hughes (2008) menyatakan bahwa langkah awal memperbaiki pelayanan yang berkualitas adalah keselamatan, sedang kunci dari pelayanan bermutu dan aman adalah membangun budaya keselamatan pasien. Menurut Mitchell dalam Hughes (2008), perawat merupakan kunci dalam pengembangan mutu melalui keselamatan pasien.

Peningkatan pengetahuan merupakan dampak yang diharapkan dari pelatihan mutu dan keselamatan pasien. Pelatihan merupakan salah satu sarana menambah kebutuhan akan pengetahuan baru dan untuk meningkatkan kinerja individu dan kinerja sistem (Henriksen \& Dayton, 2006).

Marquis dan Huston (2006) menyatakan bahwa program pengembangan staf melalui pelatihan dan pendidikan merupakan program yang efektif untuk meningkatkan produktifitas bagi perawat. 
Dukungan yang adekuat dalam bentuk pelatihan professional dan pengembangan pengetahuan merupakan salah satu upaya untuk menciptakan lingkungan kerja yang positif bagi perawat agar asuhan yang aman dapat diberikan (ICN, 2007). Penelitian ini bertujuan untuk mengurai pengaruh pelatihan keselamatan pasien terhadap pemahaman perawat pelaksana dalam penerapan keselamatan pasien di RS XX.

\section{Metode}

Penelitian ini menggunakan desain penelitian Quasi Experiment dengan pendekatan pretestposttest with control group design untuk mengukur pengaruh pelatihan keselamatan pasien terhadap pemahaman perawat pelaksana tentang penerapan keselamatan pasien. Populasi penelitian adalah seluruh perawat pelaksana di Rumah Sakit XX dengan 124 orang sebagai kelompok eksperimen dan 134 orang di RS XY sebagai kelompok kontrol. Teknik pengambilan sampel menggunakan teknik total sampling dengan kriteria inklusi yang telah ditetapkan 83 perawat untuk kelompok eksperimen dan 83 perawai untuk kelompok kontrol.

Pengumpulan data karakteristik dan pemahaman perawat pelaksana tentang keselamatan pasien sebelum (pre-test) dan setelah (post-test) pelatihan dilakukan menggunakan kuesioner yang terdiri dari 45 butir pertanyaan tertutup dengan 4 pilihan jawaban. Uji validitas dan reliabilitas dilakukan dengan menggunakan item total correlation dan nilai Alpha Cronbach.

Analisis univariat data kategorik menggunakan distribusi frekuensi dan proporsi, analisis bivariat menggunakan $t$-test dan korelasi pearson product moment sedangkan multivariat menggunakan korelasi linier ganda.

Tabel 1. Perbedaan Pemahaman Perawat Pelaksana pada Kelompok Eksperimen dan Kelompok Kontrol Sebelum dan Setelah Pelatihan

\begin{tabular}{lllcccc}
\hline \multicolumn{1}{c}{ Kelompok } & Pemahaman & Mean & Median & SD & SE & p \\
\hline \multirow{2}{*}{ Eksperimen } & a. Pre-test & 22,89 & 23 & 3,725 & 0,41 & 0,000 \\
& b. Post-test & 35,11 & 36 & 2,867 & 0,31 & \\
& Selisih & 12,22 & & 3,633 & 0,40 & \\
\multirow{2}{*}{ Kontrol } & a. Pre-test & 19,99 & 20 & 4,261 & 0,47 & 0,417 \\
& b. Post-test & 19,67 & 20 & 4,379 & 0,48 & \\
& Selisih & $-0,31$ & & 3,499 & 0,38 & \\
\hline
\end{tabular}

\section{Hasil}

\section{Pemahaman Perawat tentang Keselamatan Pasien}

Nilai rata-rata pemahaman perawat pelaksana kelompok eksperimen mengenai keselamatan pasien sebelum pelatihan (pre-test) adalah 22,89, sedangkan pada kelompok kontrol nilai pre-test adalah 19,99. Hasil ini menunjukkan bahwa nilai rata-rata pemahaman perawat pelaksana pada kelompok eksperimen sebelum pelatihan (pre-test) lebih tinggi 2,9 dibandingkan dengan kelompok kontrol.

Nilai rata-rata pemahaman perawat pelaksana pada kelompok eksperimen mengenai keselamatan pasien setelah pelatihan (post-test) adalah 35,11, sedangkan pada kelompok kontrol adalah 19,67. Hasil ini menunjukkan nilai rata-rata pemahaman perawat pelaksana pada kelompok eksperimen setelah pelatihan (post-test) lebih tinggi 15,44 dibandingkan dengan kelompok kontrol. 


\section{Perbedaan Pemahaman Perawat}

Tabel 1 menunjukkan bahwa pada kelompok eksperimen terdapat perbedaan yang bermakna antara pemahaman perawat pelaksana RS XX sebelum dan setelah pelatihan $(p=0,000 ; \alpha=0,05)$. Hal ini berarti pemberian pelatihan pada kelompok eksperimen meningkatkan pemahaman perawat pelaksana di RS XX. Sedangkan pada kelompok kontrol, hasil menunjukkan bahwa tidak terdapat perbedaan nilai pemahaman pre-test dan post-test pada kelompok kontrol setelah pelatihan pada kelompok eksperimen $(p=0,417, \alpha=0,05)$.

Tabel 2 menunjukkan bahwa terdapat perbedaan yang bermakna pada nilai rata-rata pemahaman perawat pelaksana pada kelompok eksperimen dan kontrol mengenai penerapan keselamatan pasien sebelum mendapatkan pelatihan (pre-test) $(p=0,000 ; \alpha=0,05)$. Selain itu, didapatkan juga hasil bahwa ada perbedaan yang bermakna antara rata-rata pemahaman perawat pelaksana kelompok eksperimen dan kontrol setelah pelatihan (post-test) diberikan pada kelompok eksperimen $(p=0,000 ; \alpha=0,05)$. Hal ini dapat disimpulkan bahwa pelatihan terhadap kelompok eksperimen menimbulkan adanya perbedaan pada pemahaman perawat pelaksana tentang penerapan keselamatan pasien pada kelompok eksperimen dan kelompok kontrol.
Tabel 3 menunjukkan tidak ada hubungan antara umur dengan pemahaman perawat pelaksana setelah diberikan pelatihan keselamatan pasien pada kelompok eksperimen $(p=0,460 ; \alpha=0,05)$ dan kelompok kontrol ( $p=0,373 ; \alpha=0,05)$. Lama kerja juga tidak berhubungan dengan pemahaman perawat pelaksana setelah diberikan pelatihan pada kelompok eksperimen $(p=0,424 ; \alpha=0,05)$ dan kelompok kontrol $(p=0,285 ; \alpha=0,05)$.

Tabel 4 menunjukkan bahwa tidak ada hubungan antara jenis kelamin dengan pemahaman perawat pelaksana pada kelompok eksperimen setelah pelatihan $(\mathrm{p}=0,784, \alpha=0,05)$ dan kelompok kontrol $(p=0,279, \alpha=0,05)$. Status pernikahan perawat pelaksana tidak berhubungan dengan pemahaman perawat pelaksana mengenai keselamatan pasien kelompok eksperimen setelah pelatihan $(p=0,637$, $\alpha=0,05)$ dan kelompok kontrol $(p=0,801, \alpha=0,05)$. Hasil analisis menunjukkan tidak ada hubungan status kepegawaian dengan pemahaman perawat pelaksana kelompok eksperimen $(\mathrm{p}=0,123 ; \alpha=$ $0,05)$ dan kelompok kontrol $(p=0,052 ; \alpha=0,05)$.

\section{Faktor yang Mempengaruhi Pemahaman Perawat}

Tabel 5 menunjukkan status kepegawaian dapat menjelaskan tentang variasi pemahaman perawat pelaksana pada kelompok eksperimen $(2,9 \%)$,

Tabel 2. Perbedaan Pemahaman Perawat Pelaksana pada Kelompok Eksperimen dan Kelompok Kontrol Sebelum dan Setelah Pelatihan pada Kelompok Eksperimen

\begin{tabular}{|c|c|c|c|c|c|}
\hline Variabel & $\mathbf{n}$ & $\begin{array}{c}\text { Mean } \\
\text { Median }\end{array}$ & SD & SE & $\mathbf{p}$ \\
\hline $\begin{array}{l}\text { Pre-test } \\
\text { a. Kelompok Eksperimen }\end{array}$ & 83 & $\begin{array}{c}22,89 \\
23\end{array}$ & 3,725 & 0,409 & 0,000 \\
\hline b. Kelompok Kontrol & 83 & $\begin{array}{c}19,99 \\
20\end{array}$ & 4,261 & 0,648 & \\
\hline $\begin{array}{l}\text { Post-test } \\
\text { a. Kelompok Eksperimen }\end{array}$ & 83 & $\begin{array}{c}35,11 \\
36\end{array}$ & 2,867 & 0,315 & 0,000 \\
\hline b. Kelompok Kontrol & 83 & $\begin{array}{c}19,67 \\
20\end{array}$ & 4,379 & 0,481 & \\
\hline
\end{tabular}


dan sisanya adalah disebabkan faktor lain. Hal ini menunjukan bahwa peningkatan pemahaman kelompok eksperimen secara bermakna disebabkan intervensi berupa pelatihan keselamatan pasien, bukan akibat pengaruh karakteristik individu sebagai variabel confounding.

\section{Pembahasan}

Kemampuan kognitif seseorang mempengaruhi kemampuan individu tersebut dalam melakukan tindakan yang tidak menimbulkan risiko terhadap keselamatan pasien. Pengetahuan merupakan kepercayaan yang dapat dipertanggungjawabkan serta sesuatu yang eksplisit dan terpikirkan (Krough, Ichiyo, \& Nonaka, 2000 dalam Thite, 2004; Cho, 1998, dalam Setiarso, Harjanto, Triyono, \& Subagyo, 2009). Menurut Baron dan Greenberg (200), pengetahuan merupakan sebuah perubahan yang relatif menetap dalam perilaku yang dihasilkan dari pengalaman.

Organisasi yang ingin mengembangkan budaya belajar yang efektif perlu memetakan pengetahuan yang dimiliki oleh staf Riset Delphi Group yang dikemukakan dalam Setiarso, et al. (2009), menemukan $45 \%$ aset pengetahuan tersimpan dalam pikiran staf dalam bentuk pengetahuan dan pengalaman, sedangkan sisanya berada dalam dokumen kertas dan dokumen elektronik dalam berbagai bentuk. Hal ini berarti hasil penelitian ini merupakan gambaran nyata pemahaman awal perawat pelaksana mengenai keselamatan pasien pada kedua rumah sakit tempat penelitian.
Adanya perbedaan mendasar pemahaman yang dimiliki perawat pelaksana mengenai keselamatan pasien pada kedua kelompok dalam penelitian ini yang bersifat individual dan sangat tergantung pada keterpaparan seseorang tentang keselamatan pasien. Pengetahuan staf merupakan investasi yang sangat penting dalam organisasi. Rivai dan Sagala (2009) menyatakan bahwa kemampuan staf dalam suatu bidang kerja tidak menjamin bahwa staf tersebut kompeten dan sukses dalam melakukan pekerjaannya.

Setiarso, et al. (2009) menyatakan bahwa budaya lingkungan dalam bentuk nilai dan kepercayaan, motivasi dan komitmen, serta insentif untuk upaya berbagi pengetahuan dalam organisasi merupakan suatu hal yang penting dalam program pengelolaan pengetahuan dalam organisasi. Cahyono (2008) menyatakan bahwa pengetahuan SDM kesehatan, termasuk perawat adalah hal yang berhubungan dengan komitmen yang sangat diperlukan dalam upaya untuk membangun budaya keselamatan pasien.

Peneliti berpendapat bahwa pengetahuan awal staf mengenai pekerjaannya dipengaruhi oleh banyak faktor yang ada dalam suatu organisasi. Upaya membangun pengetahuan SDM yang didukung oleh kebijakan merupakan salah satu cara inovasi/ pembaharuan yang tepat untuk memungkinkan staf memiliki kemampuan dan tanggung jawab sesuai tuntutan perubahan pada era globalisasi yang disertai dengan persaingan di berbagai bidang.

Tabel 3. Hubungan Umur dan Lama Kerja dengan Pemahaman Perawat Pelaksana setelah Diberikan Pelatihan Keselamatan Pasien

\begin{tabular}{lll}
\hline \multicolumn{1}{c}{ Variabel } & $\mathbf{R}$ & $\mathbf{p}$ \\
\hline Umur & & \\
a. Kelompok Ekperimen & 0,082 & 0,460 \\
b. Kelompok Kontrol & 0,099 & 0,373 \\
Lama Kerja & & \\
a. Kelompok Ekperimen & 0,089 & 0,424 \\
b. Kelompok Kontrol & 0,119 & 0,285 \\
\hline
\end{tabular}


Analisis peneliti terkait hal tersebut adalah upaya meningkatkan pengetahuan tetap merupakan suatu hal penting khususnya dalam konteks keselamatan pasien. Hal ini didukung pendapat Notoatmodjo (2009) yang menyatakan bahwa pengetahuan yang menunjang keterampilan perlu diberikan agar staf dapat melakukan tugasnya berdasarkan teori-teori yang dapat dipertanggungjawabkan.

Sejalan dengan hal ini, Henriksen, Joseph, dan Zayas-Caban (2009) menyatakan keterbatasan pengetahuan SDM memiliki peran penting dalam menyebabkan keterbatasan institusi pelayanan untuk mengelola pelayanan yang berorientasi pada keselamatan pasien. Hal ini berarti keterbatasan pengetahuan merupakan hal kunci sangat perlu dipertimbangkan demi keamanan asuhan yang diberikan oleh tenaga kesehatan termasuk perawat.

Pelatihan dinyatakan sebagai bagian pendidikan yang menyangkut proses belajar untuk memperoleh dan meningkatkan keterampilan di luar sistem pendidikan yang berlaku dalam waktu yang relatif singkat. Keterampilan yang dimaksud dalam hal ini adalah keterampilan dalam berbagai bentuk antara lain physical skil, intelectual skill, social skill, dan managerial skill (Rivai \& Sagala, 2009). Jika dikaitkan dengan pendapat tersebut, maka pelatihan dalam penelitian ini merupakan pelatihan yang berorientasi pada peningkatan intelectual skill yang berhubungan dengan keselamatan pasien.

Pelatihan yang diberikan terhadap staf akan membawa pengaruh terhadap proses kognitif yang mendasari tindakan individu. Teori kognitif yang dikemukakan Rasmussen, Reason, dan Norman dalam Cahyono (2008) menguatkan teori tentang model perbuatan manusia yang didasarkan pada konsep kognitif. Proses analisis secara sadar dalam bentuk berpikir sebelum mengambil suatu keputusan merupakan sebuah gambaran kontribusi knowledge based level dalam pencegahan suatu kesalahan yang dilakukan manusia. Proses untuk memahami kondisi abnormal yang mengancam kehidupan pasien dengan deteksi risiko dan menentukan langkah koreksi yang tepat dalam lingkup keperawatan maupun dengan melibatkan tenaga kesehatan yang lain merupakan salah satu bentuk kegiatan kognitif dalam tatanan knowledge based level.

Tidak adanya stimulus berupa pelatihan pada kelompok kontrol sehingga hasil penelitian ini menunjukkan perbedaan yang bermakna antara kelompok perawat yang diberi pelatihan dan yang tidak diberi pelatihan. Sesuai dengan teori Law of Response by Analogy yang dikemukakan oleh Thorndike dalam Suryabrata (2008), menjelaskan bahwa individu cenderung akan bereaksi dan menampilkan respon terhadap hal tertentu yang dihadapinya. Hal ini berarti bahwa tanpa upaya meningkatkan pengetahuan melalui pelatihan pada kelompok kontrol maka tidak akan terjadi respon mengenai hal tertentu dan seseorang cenderung hanya akan menampilkan keterampilan kognitif yang telah ada pada dirinya saja.

Marquis dan Huston (2006) yang menyatakan bahwa pengetahuan individu yang diperoleh dari pelatihan dalam pekerjaannya termasuk dalam upaya pengembangan bermakna terhadap tingkat kebutuhan perawat akan pengetahuan. Pelatihan dalam lingkup mutu dan keselamatan merupakan salah satu sarana untuk menambah kebutuhan akan pengetahuan baru dan untuk meningkatkan kinerja individu dan kinerja sistem (Henriksen \& Dayton, 2006). Sedangkan, McCutcheon, et al. (2006) merekomendasikan SDM keperawatan memiliki kebutuhan yang besar untuk mendapat pendidikan dan pelatihan berkelanjutan dalam berbagai jenjang untuk mendukung penerapan keselamatan pasien.

Menurut Rivai dan Sagala (2009), bahwa pelatihan memiliki manfaat, yaitu berupa tanggung jawab dan prestasi yang lebih dapat diinternalisasi, meningkatnya pengetahuan, keterampilan, sikap serta membantu menghilangkan rasa takut dalam menghadapi tugas baru. Lebih lanjut manfaat yang akan dirasakan dari pelatihan yaitu dapat terbentuk sikap lebih positif terhadap orientasi yang akan dicapai organisasi dan sikap moral yang lebih baik. 
Tabel 4. Hubungan Jenis Kelamin, Status Pernikahan, dan Status Kepegawaian dengan Pemahaman Kelompok eksperimen dan Kelompok Kontrol Setelah Pelatihan Keselamatan Pasien

\begin{tabular}{|c|c|c|c|c|c|}
\hline Variabel & $\bar{n}$ & Mean & SD & SE & $\mathbf{p}$ \\
\hline \multicolumn{6}{|l|}{ Kelompok E ksperimen } \\
\hline \multicolumn{6}{|l|}{ Jenis Kelamin: } \\
\hline Laki-laki & 8 & 35,58 & 3,021 & 1,086 & 0,784 \\
\hline Perempuan & 75 & 35,08 & 2,870 & 0,331 & \\
\hline \multicolumn{6}{|l|}{ Status Pernikahan: } \\
\hline Menikah & 58 & 35,21 & 2,783 & 0,365 & 0,637 \\
\hline Tidak Menikah & 25 & 34,55 & 3,100 & 0,620 & \\
\hline \multicolumn{6}{|l|}{ Status Kepegawaian: } \\
\hline Pegawai Tetap & 56 & 35,45 & 2,600 & 0,347 & 0,123 \\
\hline Pegawai Kontrak & 27 & 34,41 & 3,296 & 0,634 & \\
\hline \multicolumn{6}{|l|}{ Kelompok Kontrol } \\
\hline \multicolumn{6}{|l|}{ Jenis Kelamin: } \\
\hline Laki-laki & 4 & 22,00 & 6,532 & 3,266 & 0,279 \\
\hline Perempuan & 79 & 19,56 & 4,269 & 0,480 & \\
\hline \multicolumn{6}{|l|}{ Status Pernikahan: } \\
\hline Menikah & 60 & 19,77 & 3,748 & 0,484 & 0,801 \\
\hline Tidak Menikah & 23 & 19,43 & 5,806 & 1,211 & \\
\hline \multicolumn{6}{|l|}{ Status Kepegawaian: } \\
\hline Pegawai Tetap & 58 & 20,28 & 4,392 & 0,577 & 0,052 \\
\hline Pegawai Kontrak & 25 & 18,28 & 4,098 & 0,820 & \\
\hline
\end{tabular}

Jika dihubungkan dengan upaya untuk membangun budaya keselamatan maka kemanfaatan ini akan berkembang menjadi investasi yang bernilai positif meningkatkan peran perawat dalam membangun budaya keselamatan.

Hasil penelitian pada kelompok eksperimen yang menunjukkan ada perbedaan pemahaman sebelum dan setelah pelatihan membuktikan pelatihan dapat mempengaruhi pemahaman perawat pelaksana secara positif. Perbedaan pemahaman sebelum dan setelah pelatihan yang diberikan terhadap perawat pelaksana pada kelompok eksperimen mengenai penerapan keselamatan pasien dalam pelayanan keperawatan merupakan peningkatan hasil yang diharapkan melalui pemberian intervensi berupa pelatihan. Hal ini sejalan pendapat Rivai dan Sagala (2009) yang menyatakan jika kemampuan peserta pelatihan meningkat secara bermakna, yang artinya program pelatihan secara aktual bisa menyebabkan terjadi perbedaan kemampuan. Program pelatihan dapat dikatakan berhasil apabila peningkatan kemampuan dapat memenuhi kriteria evaluasi dan dapat diubah ke pekerjaan serta mengakibatkan perubahan sikap yang diukur dengan meningkatkan pelaksanaan pekerjaan. 
Wise dan Kowalski (2006) menyatakan pelatihan akan memungkinkan organisasi kesehatan untuk memberikan pelayanan yang luar biasa terhadap pasien dan mempertahankan sumber-sumber nilai yang dimiliki organisasi melalui upaya untuk membangun organisasi yang pembelajar. Senada dengan yang dikemukakan oleh Cahyono (2008), menyatakan bahwa pengetahuan untuk mendukung Learning Culture yang ada dalam suatu organisasi sangat berhubungan dengan perubahan budaya keselamatan pasien. Hal ini membuktikan bahwa pemberian pelatihan mengenai keselamatan pasien jika dilakukan secara konsisten akan berdampak terhadap budaya yang optimal untuk menjamin keselamatan pasien melalui perubahan organisasi menjadi organisasi yang pembelajar dan juga akan sangat mendukung tercipta budaya keselamatan pasien.

Proses kognitif untuk meningkatkan pengetahuan melalui belajar yang ada dalam kegiatan pelatihan staf tidak terlepas dari makna konsep belajar. Menurut Suryabrata (2008), bahwa pada dasarnya belajar akan menimbulkan perubahan perilaku baik aktual maupun potensial. Sejalan dengan hal ini, Robbins (2001) dengan jelas mengungkapkan pola penerimaan pengetahuan dan pembelajaran yang ada dalam kegiatan pelatihan staf merupakan hal yang penting untuk diperhatikan dalam proses pemberian pelatihan.

Sejalan dengan hal ini Quaid, Thao, dan Denham (2010) mengungkapkan internalisasi pengetahuan ke dalam nilai-nilai individu mengenai keselamatan pasien merupakan hal yang harus diupayakan dan menjadi dasar untuk belajar dari kejadian melalui diskusi mengenai kejadian yang berhubungan dengan keselamatan pasien. Perubahan perilaku yang didasari pada perubahan kemampuan kognitif individu dipengaruhi oleh banyak hal antara lain; proses emosional, internal, dan pribadi. Kombinasi pengalaman dan konseptualisasi merupakan kondisi pembelajaran yang paling baik bagi staf (Gillies, 1994).

\section{Kesimpulan}

Hasil penelitian membuktikan bahwa setelah dilakukan pelatihan keselamatan pasien terhadap perawat pelaksana menyebabkan peningkatan pemahaman perawat pelaksana tentang penerapan keselamatan pasien yang dipengaruhi perubahan kognitif selama proses pelatihan. Penelitian ini telah mengidentifikasi pengaruh dari pelatihan keselamatan pasien terhadap pemahaman perawat pelaksana di RS XX. Hasil penelitian ini juga menunjukkan bahwa peningkatan pemahaman pada kelompok eksperimen tidak dipengaruhi oleh karakteristik individu perawat pelaksana (MS, SW, HP).

\section{Referensi}

Baron, R.A., \& Greenberg, J. (2000). Behaviour in organizations (7th Ed.). New Jersey: Prentice Hall.

Cahyono, S.B. (2008). Membangun budaya keselamatan pasien dalam praktik kedokteran. Yogyakarta: Penerbit Kanisius.

Gillies, D.A. (1994). Nursing management: A system approach (3rd Ed.). Philadelphia: WB Saunders Company.

Henriksen, K., \& Dayton, E. (2006). Issues in the design of training for quality and safety. Quality and Safety Health Care, 15 (1), 17-24.

Tabel 5. Model Pemahaman Perawat Pelaksana Kelompok Eksperimen

\begin{tabular}{cccccc}
\hline Variabel & B & Beta & Sig. & R Square & p \\
\hline Constan & 36,485 & & & & \\
Status Kepegawaian & - & - & 0,123 & 0,029 & 0,123 \\
& 1,039 & 0,171 & & & \\
\hline
\end{tabular}


Henriksen, K., Joseph, A., \& Zayas-Caban, T. (2009). The human factors of home health care: A conceptual model for examining safety and quality concerns. Journal of Patient Safety, 5 (4), 229236.

Hughes, R.G. (2008). Patient safety and quality: An evidence-based handbook for nurses. Rockville MD: Agency for Healthcare Research and Quality Publications. Diperoleh dari http://www.ahrq.gov.

International Council of Nurse (ICN) \& World Health Organization. (2007). Islamabad declaration on strengthening nursing and midwifery. Diperoleh dari http://www.icn.ch.

Marquis, B.L., \& Huston, C.J. (2006). Leadership roles and management functions in nursing: Therory and application (5th Ed.). Philadelphia: Lippincott Williams \& Wilkins.

McCutcheon, A.S., et al. (2006). Staffing for safety: A synthesis of the evidence on nurse staffing and patient safety. Diperoleh dari http:// www. chsrf.ca.

Notoatmodjo. (2009). Manajemen sumber zaya manusia. Jakarta: PT Rineka Cipta.

Quaid, D., Thao, J., \& Denham, C.R. (2010). Story power: The secret weapon. Journal Patient Safety, 6 (1), 5-14.
Rivai, V., \& Sagala, E.J. (2009). Manajemen sumber daya manusia untuk perusahaan: Dari teori ke praktik (Edisi Ke-2). Jakarta: Rajawali Pers.

Robbins, S.P. (2001). Organizational behavior: Concepts, controversies, \& applications (9th Ed.). New Jersey: Prentice Hall International.

Setiarso, B., Harjanto, N., Triyono, \& Subagyo, H. (2009). Penerapan knowledge management pada organisasi. Yogyakarta: Graha Ilmu.

Suryabrata, S. (2008). Psikologi pendidikan. Jakarta: PT Raja Grafindo Persada.

Takagi, T., \& Nakanishi, A. (2007). Security, safety and high reliability: Organizations in complex socio-technical systems. International Society for the Systems Sciences. Diperoleh dari http:// journals.isss.org/index.php/proceedings $51 \mathrm{st} /$ article/viewFile/560/305.

Thite, M. (2004). Managing people in the new economy: Targeted HR practices that persuade people to unlock their knowledge. New Delhi: Sage Publications.

Wise, P.S.Y., \& Kowalski, K.E. (2006). Beyond leading and managing nursing administration for the future. USA: Mosby. 